\title{
Dyad of CD40/CD40 Ligand Fosters Neuroinflammation at the Blood-Brain Barrier and Is Regulated via JNK Signaling: Implications for HIV-1 Encephalitis
}

\author{
Servio H. Ramirez, ${ }^{1}$ Shongshan Fan, ${ }^{1}$ Holly Dykstra, ${ }^{1}$ Nancy Reichenbach, ${ }^{1}$ Luis Del Valle,,${ }^{1,2}$ Raghava Potula, ${ }^{1}$ \\ Richard P. Phipps, ${ }^{3,4}$ Sanjay B. Maggirwar, ${ }^{3}$ and Yuri Persidsky ${ }^{1}$ \\ Departments of ${ }^{1}$ Pathology and Laboratory Medicine, and ${ }^{2}$ Neuroscience, Temple University School of Medicine, Philadelphia, Pennsylvania 19140, \\ and Departments of ${ }^{3}$ Microbiology \& Immunology, and ${ }^{4}$ Environmental Medicine, University of Rochester School of Medicine, Rochester, New York 14642
}

\begin{abstract}
Human immunodeficiency virus 1 (HIV-1) infection may result in activation of peripheral monocytes followed by their infiltration into the CNS, where the release of proinflammatory mediators causes neurologic disease. Previously, we detected high levels of soluble CD40 ligand (CD40L) in CSF and plasma of HIV-infected patients with cognitive impairment. We now show that CD40, a receptor for CD40L, is highly expressed in brain endothelial cells of patients affected by HIV-1 encephalitis (HIVE), suggesting an important role for the CD40/CD40L dyad in regulating blood-brain barrier (BBB) functions. This concept was further supported by in vitro experiments. Exposure of primary human brain microvascular endothelial cells (BMVECs) to CD40L upregulated the expression of adhesion molecules intracellular adhesion molecule-1 and vascular cell adhesion molecule-1, which caused a fourfold increase in monocyte adhesion to BMVECs and stimulated migration across an in vitro BBB model. Investigations into the intracellular signaling pathways that govern these events revealed that cJUN-N-terminal kinase (JNK) is critical to CD40 activation in the BMVECs. CD40L induced activation of mixed-lineage-kinase-3 and JNK, leading to the subsequent activation of cJUN/AP-1 (activating-protein-1). JNK inhibition in the BMVECs prevented CD40L-mediated induction of adhesion molecules, monocyte adhesion, and transendothelial migration. These new findings support the concept that the CD40/CD40L dyad plays an important role in HIVE neuroinflammation.
\end{abstract}

\section{Introduction}

Despite the introduction of highly active antiretroviral therapy (HAART), which efficiently suppresses viral replication and normalizes immunologic parameters, a significant number of human immunodeficiency virus 1 (HIV-1)-infected patients show progressive loss of cognitive abilities. These cognitive deficits are collectively termed HIV-associated neurocognitive disorder (HAND) (Boissé et al., 2008; Minagar et al., 2008). The pathogenesis of HAND involves activation of monocytes and their subsequent recruitment into the CNS, altering blood-brain barrier (BBB) function and resulting in HIV-1 encephalitis (HIVE) (Persidsky et al., 2006a). The effector molecules and mechanisms that regulate monocyte migration across the $\mathrm{BBB}$ remain poorly defined. Enhanced expression of adhesion molecules on brain microvascular endothelial cells (BMVECs) triggered by inflam-

\footnotetext{
Received Nov. 22, 2009; revised May 21, 2010; accepted May 30, 2010.

This study was supported (in part) by research funding from National Institutes of Health (NIH) Grants R01MH65151, R01AA17398, and R01AA015913 (to Y.P.); R01NS054578 (to S.B.M. and R.P.P.); P01MH64570, R01MH56838, and R01NS066801 (to S.B.M.); R01DE011390 (to R.P.P. and S.B.M.); and R01HL078603 and R01ES01247 (to R.P.P.). Human BMVECs were provided by Drs. Marlys H. Witte and Michael Bernas through contract with the University of Arizona Medical Center (Tucson, AZ). The NIH National NeuroAIDS Consortium is acknowledged for brain tissue specimens used in this study.

Correspondence should be addressed to Yuri Persidsky, Department of Pathology and Laboratory Medicine Temple University School of Medicine, 3401 N. Broad Street, Philadelphia, PA 19140. E-mail: yuri.persidsky@tuhs. temple.edu.

DOI:10.1523/JNEUROSCI.5796-09.2010

Copyright $\odot 2010$ the authors $\quad 0270-6474 / 10 / 309454-11 \$ 15.00 / 0$
}

matory mediators (Mondal et al., 2004; Ramirez et al., 2008) control leukocyte trafficking into the CNS. Increased expression of adhesion molecules and BBB permeability has been demonstrated in HAND patients (Eugenin et al., 2006). A disrupted $\mathrm{BBB}$ allows accumulation of toxic serum proteins and increased infiltration of monocytes and lymphocytes, thereby accelerating inflammation and viral entry into the CNS. HAART fails to control BBB leakage and inflammation in HAND patients (Avison et al., 2004b; Eilers et al., 2008), in part because it does not reduce the high levels of CD40 ligand (CD40L) found in the plasma and CSF of HIV-1-infected patients (Sipsas et al., 2002; Sui et al., 2007). As demonstrated in other systems (Piguet et al., 2001; Ishikawa et al., 2005; Sitati et al., 2007), high levels of soluble CD40L (sCD40L) can regulate CNS inflammation at the level of the BBB.

$\mathrm{CD} 40 \mathrm{~L}(\mathrm{CD} 154)$ is a $33 \mathrm{kDa}$ type II membrane glycoprotein from the tumor necrosis factor $\alpha$ (TNF $\alpha$ ) family. CD40L is expressed predominantly by activated leukocytes and platelets $(\mathrm{Li}$, 2008). In addition to the membrane-bound form of the protein, $31 \mathrm{kDa}$ and/or $18 \mathrm{kDa}$ versions of CD40L can be secreted or shed from activated cells. Either form of CD40L retains the ability to activate CD40, a 45 to $50 \mathrm{kDa}$ type I membrane glycoprotein expressed at a low level in resting cells of myeloid and vascular origin (Sui et al., 2007; Mancino et al., 2008; Pluvinet et al., 2008). CD40 expression is rapidly upregulated in these cells after exposure to proinflammatory mediators (Sui et al., 2007; Pluvinet et al., 2008). 
Table 1. Clinical data for human brain tissue samples

\begin{tabular}{|c|c|c|c|c|c|}
\hline $\begin{array}{l}\text { Case } \\
\text { number }\end{array}$ & HIV-1 infection & $\begin{array}{l}\text { Age } \\
\text { (year) }\end{array}$ & Gender & $\begin{array}{l}\text { Viral load } \\
\text { (copies/ml) }\end{array}$ & Other systemic diseases \\
\hline 1 & HIVE severe $^{a}$ & 37 & M & 750,000 & Pulmonary aspergillosis \\
\hline 2 & HIVE severe & 44 & M & 389,120 & Cachexia, Kaposi sarcoma of lymph nodes, chronic hepatitis \\
\hline 3 & HIVE severe & 32 & M & $1,098,947$ & Bacterial bronchopneumonia \\
\hline 4 & HIVE severe & 42 & M & 6,940 & Bacterial bronchopneumonia \\
\hline 5 & HIV $-1^{b}$ & 51 & M & 65 & Pulmonary embolus, pulmonary aspergilloma \\
\hline 6 & HIV-1 & 43 & M & 252,604 & Pneumocystis carinii pneumonia, disseminated cytomegalovirus, liver steatosis \\
\hline 7 & HIV-1 & 47 & M & 3,861 & Hepatitis C, micronodular cirrhosis, focal segmental glomerulosclerosis \\
\hline 8 & Seronegative control & 33 & $\mathrm{~F}$ & NA & Cystic fibrosis, septicemia \\
\hline 9 & Seronegative control & 55 & M & NA & Bronchopneumonia \\
\hline 10 & Seronegative control & 46 & M & NA & Hepatitis C, cirrhosis, atherosclerosis \\
\hline 11 & Seronegative control & 52 & M & NA & Status post aortic valve repair, myocardial infarction, bronchopneumonia \\
\hline
\end{tabular}

M, Male; F, female; NA, not applicable.

a Severe HIVE is defined by the expression of human leukocyte antigen HLA-DR on 80 to $90 \%$ of microglia; HIV- 1 infection of ramified microglia; formation of 1 to 2 microglial nodules and 25 to 50 infiltrating macrophages per $5 \times 10$-power fields; and abundant multinucleated cells, as described by Mathur et al. (2004).

${ }^{b}$ No significant neuropathologic changes were found.

Elevated levels of sCD40L are found in a variety of diseases in which sCD40L is thought to initiate or potentiate inflammation (Tsakiris et al., 2000; Heeschen et al., 2003; Devaraj et al., 2006). Inflammatory conditions increase the expression of the CD40 receptor on the surface of endothelial cells and the shedding of the ligand (Chai et al., 2006). In HIV-1 neuropathogenesis, a connection between CD40 and microglia has been established. Upregulation of CD40 expression has been detected on microglia of HIV-1-infected brain tissues (D'Aversa et al., 2005). CD40L was also shown to potentiate the ability of HIV-1 protein (Tat) to activate monocytes and microglia leading to the secretion of neurotoxic inflammatory mediators (Sui et al., 2007).

A role for the CD40/CD40L dyad in brain endothelium remains largely unknown. Herein, we detected high levels of CD40 on brain endothelium in patients with HIVE. We demonstrated that engagement of endothelial CD40 promotes adhesion and migration of leukocytes across an in vitro BBB model. Our studies also show that CD40 signaling converges to the cJUN-N-terminal kinase (JNK) signaling pathway, which was found to mediate the effects of CD40L on the endothelial regulation of leukocyte adhesion and migration.

\section{Materials and Methods}

Reagents. Recombinant human sCD40L was purchased from ProSpec. Recombinant membrane-bound CD40L [CD40L(M)] and corresponding control membranes that lack CD40L were generated in a Baculovirus-based expression system (Ray et al., 2005; Sui et al., 2007). Neutralizing antibodies to human CD40, recombinant human TNF $\alpha$, and CC chemokine ligand 2 (CCL2)/monocyte chemoattractant protein 1 (MCP-1) were purchased from R\&D Systems. The following inhibitors were obtained from Calbiochem: Janus kinase (JAK) inhibitor P6; JAK-3 inhibitor-VI ( $3^{\prime}$-pyridyl oxindole derivative); I $\kappa \mathrm{B}-\alpha$ kinase (IKK) inhibitor-X [N-(6chloro-9H-b-carbolin-8-yl) nicotinamide)]; p38 inhibitor SB202190; extracellular signal-regulated kinase (ERK) inhibitor FR180204; JNK inhibitor I [(L)-HIV-TAT ${ }_{48-57}-\mathrm{PP}_{-} \mathrm{JBD}_{20}$ ]; and JNK inhibitor II (SP600125). Unless specified, all other reagents were purchased from Sigma-Aldrich.

Cell culture. Primary BMVECs were supplied by Dr. Michael Bernas and Dr. Marlys Witte (University of Arizona, Tucson, AZ). BMVECs were isolated from vessels of normal tissue derived from brain resections performed for the treatment of intractable epilepsy. The BMVEC cultures were used until passage 5 and were expanded in DMEM/F-12 media supplemented with $10 \%$ heat-inactivated fetal bovine serum (FBS), endothelial cell growth supplement (ECGS) (BD Bioscience), heparin (1 $\mathrm{mg} / \mathrm{ml}$, Sigma), amphotericin B (2.5 $\mu \mathrm{g} / \mathrm{ml}$, Invitrogen), penicillin (100 $\mathrm{U} / \mathrm{ml}$, Invitrogen), and streptomycin (100 $\mu \mathrm{g} / \mathrm{ml}$, Invitrogen). Before experimentation, BMVEC monolayers were placed with media contain- ing the above supplements but lacking ECGS and heparin. Under these conditions, the BMVEC cultures were routinely evaluated for the presence of endothelial markers and barrier formation.

Primary human monocytes were supplied by the Human Immunology Core at the University of Pennsylvania (Philadelphia, PA). The cells were isolated by countercurrent centrifugal elutriation and maintained in DMEM containing heat-inactivated $10 \%$ FBS, penicillin $(100 \mathrm{U} / \mathrm{ml})$, streptomycin (100 U/ml), and L-glutamine (2 mM) (Ramirez et al., 2009), and were used within $24 \mathrm{~h}$ of isolation.

Immunofluorescence staining and image analysis. Evaluation of CD40 expression was performed on frozen brain tissue from seven HIV-1infected patients [four with severe encephalitis (Persidsky et al., 2006b) and three without evidence of encephalitis], and four seronegative agematched controls were provided by the National NeuroAIDS Consortium (Washington, DC) (Table 1). Indirect immunofluorescence was performed on serial sections cut at a thickness of $5 \mu \mathrm{m}$. Monoclonal antibodies to human CD68 (diluted 1:200, Abcam), CD163 (1:200, Santa Cruz Biotechnology), intercellular adhesion molecule-1 (ICAM-1), and vascular cell adhesion molecule-1 (VCAM-1) (diluted 1:200, R\&D Systems) or polyclonal antibodies to human CD40 (diluted 1:50, Abcam), together with rhodamine-conjugated Ulex europeus agglutinin 1 lectin (UEA-1) ( $2 \mu \mathrm{g} / \mathrm{ml}$, Vector Laboratories), were placed on sections overnight at $4^{\circ} \mathrm{C}$. Tissue sections were rinsed, and secondary antibodies conjugated to Alexa-488 (diluted 1:250, Invitrogen) were then added for $1 \mathrm{~h}$. The slides were mounted with Prolong antifade reagent containing DAPI (Invitrogen).

We performed semiquantitative image analysis to determine the upregulation of CD40 in HIVE. For each case, images from five fields were acquired with equal acquisition parameters and $<20 \times$ objective magnification for both CD40 and UEA-1 using a Coolsnap EZ CCD camera (Photometrics) coupled to a Nikon i80 Eclipse (Nikon). Up to 20 vessels (with diameters between 30 and $60 \mu \mathrm{m}$ ) per field were identified using the UEA-1 label and then were matched to the corresponding CD40 staining. The integrated intensity (average optical densities from all the pixels measured) was determined by placing a defined rectangular box $(10 \times 100 \mu \mathrm{m})$ region of interest within the CD400-labeled vessels using Axiovision imaging software (Zeiss). For display purposes, Axiovision was also used to pseudo-color the acquired fluorescence images.

Flow cytometry. Surface expression of adhesion molecules was measured in BMVECs by flow cytometry. Briefly, after various treatments $2 \times 10^{6}$ cells were placed in staining solution (2\% BSA in PBS with $0.5 \%$ $\mathrm{NaN}_{3}$ ) containing fluorophore-conjugated antibodies to CD40 (antiCD40-Phycoerythrin, R\&D Systems), CD54 (anti-ICAM-1-allophycocyanin, BD Biosciences), and CD106 (anti-VCAM-1 FITC, BD Biosciences) for $30 \mathrm{~min}$ on ice. Cells were then washed and fixed in $2 \%$ methanol-free formaldehyde (Thermo Scientific) in $1 \times$ PBS. Acquisition and analysis of the labeled cells were then performed using a FACSCalibur flow cytometer (BD Biosciences). Acquisition parameters and gating were controlled by CellQuest software (BD Biosciences). Data 
A

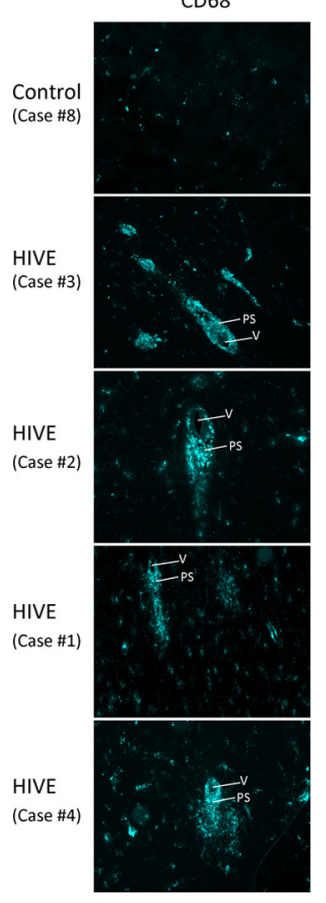

B

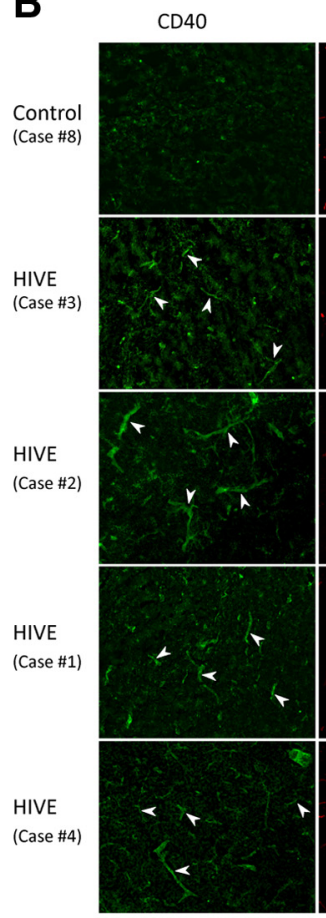

UEA-I

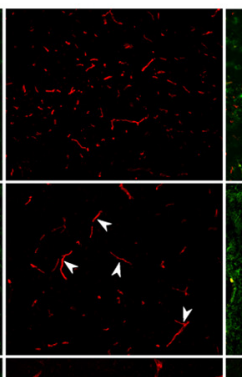

Merge of CD40 and UEA-I

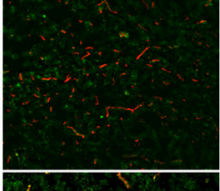

C

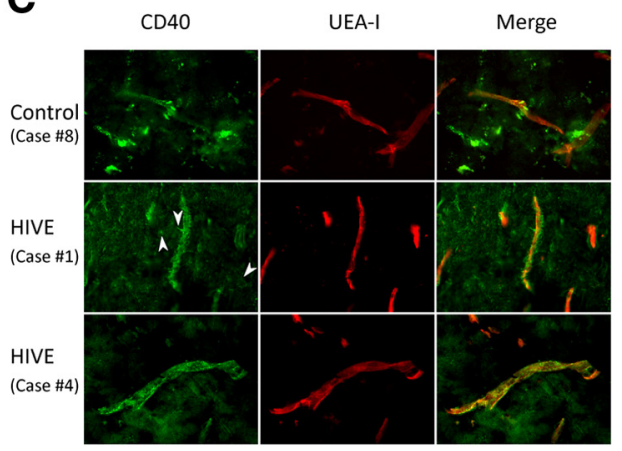

D

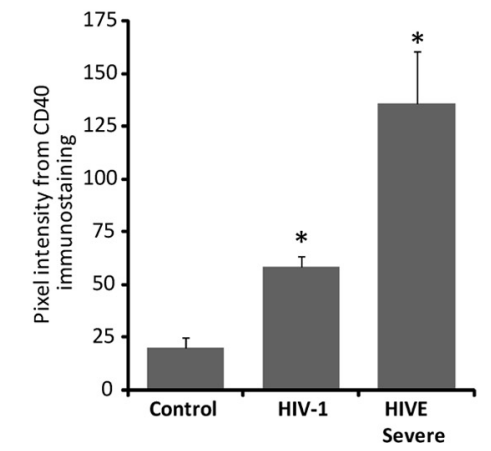

Figure 1. Upregulation of CD40 expression in microvessels in HIV-1-infected brain tissue. Frontal cortex brain tissue specimens were obtained from seven cases of HIVE of different severity (moderate to severe according to previously described criteria) (Avison et al., 2004a) along with HIVE cases and seronegative age-matched controls $(n=4)$. Serial frozen sections ( $5 \mu \mathrm{m}$ thick) were cut and stained for CD68 (monocyte-macrophage marker, cyan). On serial sections, cerebral vessels were identified by double staining with UEA-1 (red) and antibodies to CD40 (green). $A$, Infiltration of monocytes (a feature of HIVE) was confirmed by staining of CD68 (V, Vessel; PS, perivascular space). B, Although no staining for CD40 was seen in controls, there was a substantial increase in CD40 levels in HIVE (arrowheads). C, Higher magnification demonstrated minimal-to-no staining for CD40 in controls and upregulation of CD40 in HIVE. In addition, glial cells were also CD40 positive in HIVE (arrowheads) but not in controls. Stained sections were observed by immunofluorescent microscopy (objective $10 \times$ and $40 \times$ ), and digital images were acquired by a cooled CCD camera. $D$, Semiquantitative assessments of CD40 levels were performed as described in Materials and Methods. CD40 was upregulated 2.5-fold and 5-fold in HIV-positive and severe HIVE cases, respectively, compared with controls. Data are shown as mean \pm SEM. ${ }^{*} p<0.01$. Original magnification: $A, B, 100 \times ; C, 400 \times$.

analysis was performed with FlowJo software (Tree Star). The data represent the mean fluorescence intensity of gated populations (as determined by isotype-matched controls) (supplemental Fig. S1 $A, B$, available at www.jneurosci.org as supplemental material) of at least 10,000 events recorded in a single experiment, which was repeated at least three times.

Western blot. BMVEC monolayers were treated and lysed for either total protein or nuclear protein. Cell lysates were prepared using the CelLytic-M cell lysis reagent (Sigma) containing protease inhibitor mixture (Sigma) and phosphatase inhibitor mixture set I (Calbiochem). Proteins from the nuclear fraction were isolated using the CelLytic nuclear extraction kit (Sigma). The protein content in the lysate/fraction was then determined using the BCA protein assay (Thermo Scientific). Protein lysate/fraction containing $20 \mu \mathrm{g}$ of protein was mixed with $2 \times$ Laemmli (sample loading) buffer containing $\beta$-mercaptoethanol and then boiled for $5 \mathrm{~min}$. The proteins were then resolved by SDS-PAGE (4-20\% precast gels) (Thermo Scientific), followed by electrophoretic transfer to nitrocellulose membranes. The primary antibodies were diluted in $1 \times$ TBS/0.1\% Tween 20 and used to detect the following proteins: antiCD40 (diluted 1:500); anti- $\beta$-tubulin (diluted 1:2000); anti-lamin A/C (diluted 1:2000) from Abcam; anti-ERK1/2 (diluted 1:1000); antiphospho (p)-ERK1/2 thr202/tyr204 (diluted 1:1000); anti-JNK (1:500); anti-p-JNK thr183/tyr185 (diluted 1:250); anti-MLK3 (diluted 1:500); anti-p-MLK3 thr277/ser281 (diluted 1:250); anti-cJun (diluted 1:1000); and anti-p-cJun ser63 (diluted 1:500) (all purchased from Cell Signaling Technology). All antibodies (except for $\beta$-tubulin, $1 \mathrm{~h}$ at room temperature) were incubated with the membranes overnight at $4^{\circ} \mathrm{C}$ under gentle shaking. Bound primary antibodies were exposed to the corresponding species-specific peroxidase-conjugated secondary antibody (diluted 1:5000) (Thermo Scientific) for $1 \mathrm{~h}$ at room temperature and detected using the supersignal West-Femto chemluminescent substrate (Thermo Scientific), acquired on a G:Box Chemi HR16 (Syngene) gel documentation system.
Transcription factor ELISA. Evaluation of DNA binding by activated cJun was performed using the TransAM cJun transcription factor assay (Active Motif). BMVECs $\left(2 \times 10^{6}\right)$ were exposed to increasing concentrations of sCD40L or anisomysin (control) for $30 \mathrm{~min}$ followed by lysis and extraction of the nuclear fraction. Nuclear proteins $(10 \mu \mathrm{g})$ were allowed to bind to oligonucleotide-coated 96-well plates. The bound proteins were quantitated using the antibodies described above and measuring absorbance at $450 \mathrm{~nm}$ in a Spectramax M5 (Molecular Devices).

Adhesion and migration assays. Quantitative adhesion and migration assays were performed as previously described (Ramirez et al., 2008). For adhesion and migration assays, BMVECs were seeded on collagen type I-coated 96-well plates (adhesion) or on $3 \mu \mathrm{m} 24$-well tissue culture inserts (FluoroBlok, BD Bioscience) at a density of $2.5 \times 10^{4}$ cells/well. Confluent monolayers were then exposed to the indicated experimental treatments. Freshly isolated human monocytes at $5 \times 10^{6}$ cells $/ \mathrm{ml}$ were labeled with $5 \mu \mathrm{M}$ the fluorescent tracer, calcein-AM (Invitrogen). All treatments were removed from the endothelial cells before adding monocytes at $2.5 \times 10^{5}$ cells/well or insert.

For adhesion assays, the monocytes and endothelial cells were incubated together for $15 \mathrm{~min}$ and then rinsed three times with $1 \times$ PBS to eliminate nonadherent monocytes. For migration assays, the monocytes were placed for $2 \mathrm{~h}$ in the upper chamber of the tissue culture insert system, while chemoattractant CCL2/MCP-1 (50 ng/ml) was added to the lower chamber to stimulate migration. The fluorescence of adherent monocytes or migrated monocytes was measured using a Spectramax M5 fluorescence plate reader (Molecular Devices). The number of migrated monocytes was determined from external standards of known numbers of labeled monocytes. The results for adhesion are represented as the mean \pm SEM fold adhesion (number of adherent monocytes for each experimental condition divided by the basal adhesion of the untreated control). The results for migration are shown as the average fold migration \pm SEM; the fold migration is derived from the number of migrated 

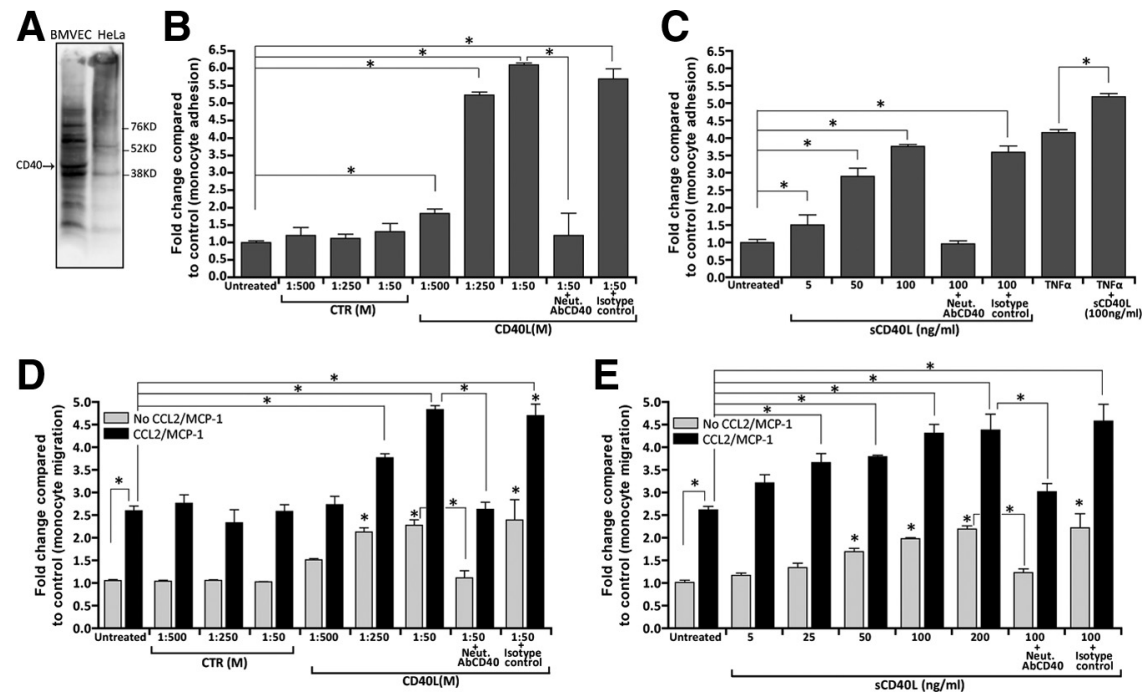

Figure 2. Brain endothelial cells exposed to CD40L increase monocyte adhesion and transendothelial migration. $A$, Basal expression of CD40 was found in BMVECs, but was undetectable in resting HeLa cells. Analysis of adhesion was performed with a fluorescence-based assay using primary human BMVECs and monocytes as described in Materials and Methods. After the formation of monolayers, the BMVECs were treated with the indicated test conditions or with $\operatorname{TNF} \alpha(20 \mathrm{ng} / \mathrm{ml})$ for $24 \mathrm{~h}$. Treatments were removed and fluorescent-labeled monocytes were added to the BMVECS. $\boldsymbol{B}$, Adhesion assay demonstrating endothelial activation and subsequent monocyte adhesion induced by increasing concentrations of membrane-bound CD40L [shown as CD40L(M)]. Control membrane [CTR(M)] preps lacking CD40L had no appreciable induction in adhesion. Coincubation of CD40L(M) with neutralizing antibodies (Neut. AbCD40) to CD40 blocked the effects of CD40L. C, Adhesion assays with sCD40L also shows a dose response in adhesion that is blocked by the presence of $\mathrm{CD} 40$-neutralizing antibodies. Transendothelial migration assays were performed as describe in Materials and Methods. The indicated treatments were added for $24 \mathrm{~h}$ and then removed, followed by monocyte addition and chemotaxis toward the relevant chemokine CCL2/MCP-1 $(50 \mathrm{ng} / \mathrm{ml}) . \boldsymbol{D}, \boldsymbol{E}$, A dose-dependent increase in monocyte migration was found after addition of $C D 40 L(M)(D)$ and sCD40L (E) to BMVEC monolayers. The effects of either form of CD40L were specific since the degree of migration induced by CD40L was eliminated by antibody neutralization. Of note, nonchemoattractant-driven migration also showed an increase in basal migration when BMVECs were stimulated with either membrane-bound or soluble CD40L. Data shown as mean \pm SEM. ${ }^{*} p<0.01$.

monocytes for each experimental condition divided by the number of migrated monocytes in the untreated, no chemoattractant control.

Statistical analysis. The values shown in all figures and those mentioned in the text represents the average \pm SEM of experiments that were conducted multiple times (as indicated). Statistical significance $(p<$ 0.05 ) was determined by performing unpaired, two-tailed Student's $t$ test or ANOVA using Prism v5 software (GraphPad Software).

\section{Results}

\section{CD40 is upregulated in brain endothelium from patients} with HIVE

To establish clinical relevance of CD40 expression in BMVECs in the context of HIV-1 infection, we evaluated the CD40 levels in the frontal cortex derived from seven HIV-1-infected patients, of which four cases were determined to be representative of severe HIVE (Persidsky et al., 1999; Persidsky et al., 2006b) and no neuropathologic changes were detected in three other cases (Table 1). As a negative control, the CD40 levels were also examined in frontal cortex obtained from seronegative patients. Since the degree of neurologic deficit in HIV-infected individuals is strongly correlated with the number of activated macrophages and microglia within the basal ganglia and frontal lobes (Persidsky et al., 1999; Avison et al., 2004b), we first verified the severity of HIVE by detecting CD68-positive cells in the perivascular spaces. Although very few CD68 cells were found in control cases, HIVE brains featured mononuclear cell infiltration (Fig. 1A) (see additional histopathology in supplemental Fig. S2A, available at www.jneurosci.org as supplemental material). Next, we examined CD40 expression by staining with anti-CD40 antibodies and double-labeling with the lectin UEA-1 to identify the microvas- culature. Control brains demonstrated a minimal level of CD40 expression (Fig. $1 B$, case 8$)$; however, CD40 expression was readily detectable in endothelial cells (Fig. $1 B$, arrowheads) in brain tissues affected by severe HIVE (Fig. $1 B$, cases 1,2 , 3 , and 4) and to a lesser extent in tissue from HIV-1-infected patients without HIVE (data not shown). Consistent with previous observations (D'Aversa et al., 2002), astrocytes and microglia in severe HIVE cases were positive for CD40 (Fig. $1 C$, cases 1 and 4 ), and no immunostaining was detected in controls (Fig. $1 C$, case 8). The increase in CD40 immunostaining seen in HIVE cases paralleled the upregulation of adhesion molecules in brain endothelium, VCAM-1 (supplemental Fig. S2 $B$, available at www.jneurosci.org as supplemental material), and to a lesser degree ICAM-1 (data not shown) compared with controls. This new finding suggested that CD40 plays a role in promoting leukocyte infiltration across the BBB.

Next, we assessed CD40 expression in brain endothelium. For each case, up to five fields were acquired at $<20 \times$ objective magnification for both CD40 and UEA-1. Up to 20 vessels per field were identified using UEA-1 staining and then matched to the corresponding CD40 labeling. The integrated intensity was measured by placing a defined rectangular region of interest on the vessel. We found that CD40 expression was upregulated over twofold in HIV-1 patients (without HIVE) and over fivefold in cases of HIVE when compared with the seronegative controls (Fig. $1 D, p<0.01$ ). These data suggest that CD40 expression is indeed increased in brain endothelium during HIVE, and levels appear elevated even in HIV-1 infection without evidence of encephalitis.

\section{CD40L promotes monocyte adhesion to and migration across human BMVECs}

Increased expression of CD40 can potentially promote leukocyte adhesion to and migration across endothelium. Indeed, augmented CD40L levels have been found in inflammatory conditions including HIV-1 CNS infection (Sui et al., 2007; Rizvi et al., 2008). However, the ability of CD40L to mediate monocyte adhesion to and/or migration across brain endothelium has not been studied. Therefore, we sought to determine whether CD40L could affect monocyte adhesion to BMVEC monolayers. We conducted immunoblot analyses and found detectable amounts of CD40 in the lysates of BMVECs, but not in negative control cells (HeLa) (Fig. 2A).

Next, we performed monocyte adhesion assays in which monolayers of BMVECs were exposed to two forms of CD40Ls, membrane-bound CD40L and CD40L(M); this form of CD40L mimics CD40L (that is expressed on the surface of activated cells) and SCD40L (similar to CD40L that is shed or released by activated cells). Doses of CD40L(M) were similar to those previously validated in cell culture (Ray et al., 2005; Ryan et al., 2005). Soluble CD40L was applied in concentrations used by other investigators (Kehry and Castle, 1994). Adhesion assays revealed that 
exposure to CD40L(M) induced a fivefold increase in the number of monocytes attaching to the BMVEC monolayers ( $p<$ 0.01) (Fig. $2 B$ ). This effect of CD40L(M) was specific to CD40L, at all doses. Exposure to equivalent amounts of control membranes that lack CD40L resulted in monocyte attachment comparable to untreated BMVECs. Similarly, sCD40L produced $\sim 3.5$-fold increase in monocyte adhesion over untreated BMVECs (Fig. $2 C)$. Increases in monocyte adhesion were completely blocked after coadministration of CD40 neutralizing antibodies, but not by addition of isotype-matched nonimmune serum (Fig. $2 B, C$ ).

Analogous to sCD40L (Sipsas et al., 2002; Sui et al., 2007), high levels of TNF $\alpha$ are also present in the blood of HIV-1infected patients especially in those with greater BBB impairment (Sharief et al., 1992). We sought to determine whether TNF $\alpha$ augments the ability of CD40L to induce monocyte adhesion. Pretreatment of BMVECs with TNF $\alpha$ induced monocyte adhesion by almost fourfold; this was further enhanced after coadministration of sCD40L, suggesting an additive effect of these two proinflammatory mediators on monocyte adhesion (Fig. 2C).

Subsequently, we tested whether CD40 engagement in BMVECs would promote monocyte passage (migration) across BMVEC monolayers. BMVECs were treated with both CD40L(M) and SCD40L, after which fluorescently labeled human monocytes were placed in the upper chamber and allowed to migrate across the BMVEC monolayer. Addition of CD40L caused a dose-dependent increase in monocyte passage across BMVEC monolayers (up to twofold, $p<0.01$ ) (Fig. $2 D, E$ ). We also used CCL2/MCP-1 as a chemoattractant implicated in HIVE pathogenesis (Persidsky et al., 1999). Application of CCL2/MCP-1 to the lower chamber of BBB construct increased monocyte migration by 2.5 -fold compared with models without chemokine addition. This effect of CCL2/MCP-1 was more intense (over fourfold increase for the highest concentration tested) in BMVEC monolayers pretreated with either CD40L configuration (Fig. 2D,E). As in the case of the adhesion, CD40L-mediated transendothelial migration was also significantly blocked by CD40 neutralization. Our data suggest that the CD40/CD40L interaction in BMVECs may play an important role in controlling trans-BBB migration of monocytes during HIVE.

\section{CD40L promotes expression of adhesion molecules in BMVECs}

To better understand how CD40 engagement regulates monocyte migration across the $\mathrm{BBB}$, we determined whether $\mathrm{CD} 40 \mathrm{~L}$ treatment caused increased expression of adhesion molecules on BMVECs. BMVECs were exposed to sCD40L for $24 \mathrm{~h}$, either alone or together with CD40 neutralizing antibodies. The cells were stained using antibodies to VCAM-1, ICAM-1, or isotype-matched nonimmune antibodies. Treatment of BMVECs with SCD40L resulted in a twofold increase in cell surface expression of VCAM-1 (Fig. 3), whereas nearly a fourfold to fivefold increase in ICAM-1 expression was observed in BMVECs under these conditions. These effects of sCD40L were completely reversed by preincubation of the cells with neutralizing antibodies to CD40. These data indicate that CD40 stimulation by CD40L promoted adhesion molecule expression.

\section{CD40L stimulates expression of adhesion molecules via activation of JNK-dependent signaling events}

To understand the molecular basis for the observed induction of ICAM-1 and VCAM-1, we determined whether sCD40L might activate specific signaling pathways, and thereby promote sCD40L-mediated effects on adhesion molecule production by BMVECs. We explored putative signaling molecules previously identified as targets for stimulation by CD40L including JAK (Klein et al., 2003), IKK (Schwabe et al., 2001), JNK, and mitogen-activated protein kinase (MAPK) family members ERK1/2 and p38 (Yu et al., 2004; Chen et al., 2006; Li and Nord, 2009) that determine activation of transcription factors such as signal transducers and activators of transcription (STAT), nuclear factor $\kappa \mathrm{B}$, and cJUN, respectively. We used specific cellpermeable pharmacological and biological inhibitors of relevant signaling molecules to dissect CD40L-induced increased expression of adhesion molecules. BMVECs were pretreated with the inhibitors for $30 \mathrm{~min}$ then coincubated with sCD40L for $24 \mathrm{~h}$, after which ICAM-1 and VCAM-1 expression was detected by FACS analysis. The JAK/STAT inhibitor (pyridone 6, $10 \mu \mathrm{M}$ ) and JAK3/STAT3 inhibitor VI (3'-pyridyl oxindole-based compound, $1 \mu \mathrm{M}$ ) produced no decrease in expression of either 
A

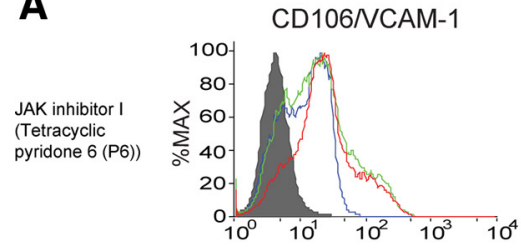

B
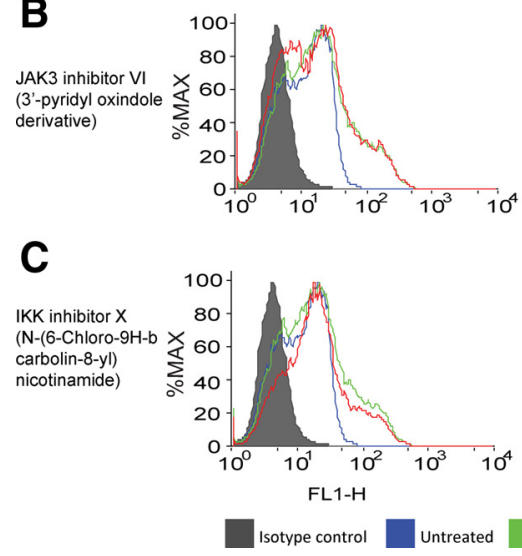

D

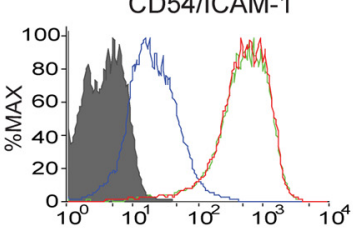

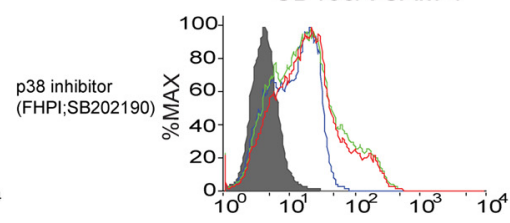
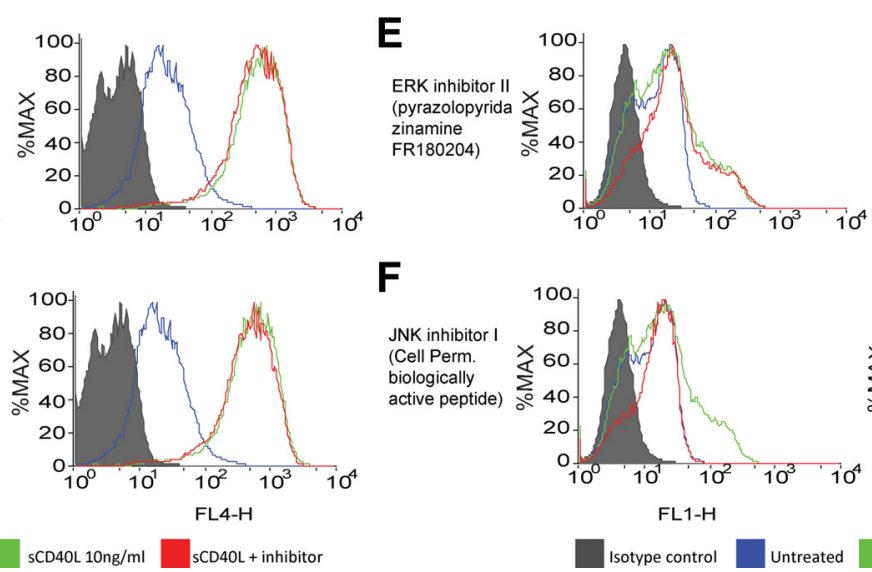

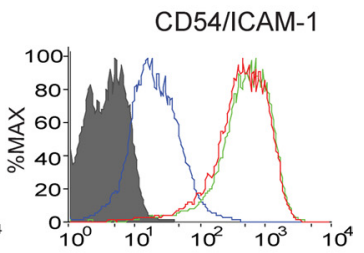

Figure 4. SCD40L induction of ICAM-1 and VCAM-1 in BMVECS is JNK dependent. FACS analyses were performed to determine which pathway was responsible for the upregulation of adhesion molecules during CD40 activation. Endothelial cells were coincubated with SCD40L and cell-permeable inhibitors to JAK1/3, IKK $\alpha$, ERK1/2, and JNK1. A-F, The following inhibitors were introduced for 30 min after coincubation with sCD40L (10 ng/ml): JAK/STAT inhibitor pyridone $6(10 \mu \mathrm{M})(\boldsymbol{A})$; JAK3/STAT3 inhibitor VI $(1 \mu \mathrm{M})$, a 3'-pyridyl oxindole-based compound (B); IKK $\alpha$ inhibitor N-(6-chloro-9H-b-carbolin-8-yl)nicotinamide (1 $\mu \mathrm{M})(\boldsymbol{C})$; p38 inhibitor FHPI (5 $\mu \mathrm{M})(\boldsymbol{D})$; ERK1/2 inhibitor FR180204 (10 $\mu \mathrm{M})(\boldsymbol{E})$; and the cell-permeable JNK-binding domain peptide inhibitor $(\boldsymbol{F})$. Histograms on the left side indicate VCAM-1 expression. Histograms on the right indicate ICAM-1 expression. The histograms are a single representation of at least three independently performed experiments showing similar results. The filled area under the curve shows the $\lg \mathrm{G}$ isotype control, the green line indicates the expression after sCD40L exposure, and the orange line indicates expression after $\mathrm{SCD} 40 \mathrm{~L}$ plus respective inhibitor.

ICAM-1 or VCAM-1 (Fig. 4). Inhibition of the IKK/NF $\kappa$ B pathway with the potent IKK ATP-competitor $N$-(6-chloro-9H-bcarbolin-8-yl)nicotinamide $(1 \mu \mathrm{M})$ only marginally diminished VCAM-1 surface levels without effect on ICAM-1 expression. Inhibition of p38 (by FHPI, $5 \mu \mathrm{M}$ ) and ERK1/2 (by FR180204, 10 $\mu \mathrm{M})$ failed to prevent CD40L-induced upregulation of adhesion molecules (Fig. 4). These results were in stark contrast to the effects of a JNK inhibitor (cell-permeable JNK-binding domain peptide) that caused a nearly complete inhibition of ICAM-1 and VCAM-1. These data indicate that enhanced expression of adhesion molecules by signaling events triggered by the CD40L-CD 40 dyad is sensitive to inhibition of JNK.

\section{CD40L activates JNK and ERK1/2 but not p38}

To test whether JNK-dependent signaling was activated by CD40L in BMVECs, we examined the ability of sCD40L to promote the phosphorylation and thus activation of mixed-lineage kinase-3 (MLK3), a molecule that targets JNK. As determined by immunoblot analyses, rapid phosphorylation of MLK3 at residues Thr-277 and Ser-281 occurred in SCD40L-exposed BMVECs (Fig. 5A). This effect indicates activation of MLK3 because autophosphorylation at Thr-277 and Ser-281 is an obligatory intermediate step of MLK3 activation, after its dimerization in response to specific stimuli (Du et al., 2005).

To test whether downstream kinases known to be activated by MLK3 were also involved in SCD40L-induced expression of adhesion molecules, cell lysates were analyzed for activation of JNK and other MAPKs, namely p38 and ERK1/2. As shown in Figure $5, B$ and $C$, immunoblots revealed enhanced phosphorylation of JNK (including both JNK1 and JNK2 isoforms of JNK) and ERK1/2, indicating activation of these kinases. However, under these conditions, phosphorylation of p38 MAPK was not de- tected (Fig. 5D), suggesting this kinase does not mediate CD40L signaling in BMVECs.

To verify whether CD40L activates JNK, additional experiments were performed in which BMVECs were exposed to sCD40L and then examined for the phosphorylation of cJUN at sites commonly targeted by JNK. Since phosphorylation of cJUN at Ser-63 rapidly triggers its translocation, we prepared nuclear extracts and subjected them to immunoblot analyses. Prompt accumulation of cJUN was observed in BMVECs treated with sCD40L (Fig. 5E). Moreover, cJUN protein detected in the nucleus was found predominantly phosphorylated at Ser-63, further suggesting activation of the JNK.

Finally, we tested whether the increased phosphorylation of cJUN in sCD40L-treated BMVECs resulted in higher DNAbinding activity of cJUN containing complexes of transcription factors (largely referred to as the AP-1 family). Nuclear extracts were prepared, and the DNA-binding activity of AP-1 was measured. AP-1 DNA-binding activity was rapidly stimulated in sCD40L-treated cells (Fig. 5F), indicating activation of AP-1.

\section{Inhibition of JNK signaling blocks monocyte adhesion and transendothelial migration stimulated by $\mathrm{SCD} 40 \mathrm{~L}$}

To test whether activation of JNK signaling mechanisms by sCD40L in BMVECs is biologically significant, we determined whether JNK inhibition could decrease the monocyte migration induced by sCD40L. BMVEC exposure to sCD40L led to a 3.3-fold increase in the number of monocytes adhering to the BMVEC monolayers $(p<0.01)$ (Fig. $6 A)$. Increased adhesion was reduced by 2 -fold and 1.6-fold in the cells exposed to sCD40L together with a JNK biological inhibitor (JBD peptide) or a pharmacological inhibitor (SP600125), respectively. To verify whether JNK signaling indeed plays a crucial role in regulation of 
monocyte adhesion, we also used a positive control, TNF $\alpha$. Treatment of BMVEC monolayers with TNF $\alpha$ increased monocyte adhesion more than fivefold, which was reduced by $60 \%$ after treatment with JNK inhibitors and is consistent with previously published data (Ramirez et al., 2008).

Next, we tested whether JNK inhibition in endothelial cells could prevent monocyte passage (migration) across BMVEC monolayers activated with sCD40L. sCD40L application increased migration by 2.2-fold, which was reduced by $30 \%$ after addition of JNK inhibitors (Fig. $6 B$ ). We used CCL2/MCP-1 as a relevant chemoattractant (applied to the lower chamber of BBB models). In the presence of CCL2/MCP-1, sCD40L treatment increased migration nearly fivefold. Remarkably, as seen without chemoattractant, JNK inhibitors reduced transendothelial migration by almost 70\% ( $p<$ 0.01 ). Thus, JNK inhibitors significantly attenuated monocyte adhesion and transendothelial migration in CD40-activated endothelial monolayers. Additionally, JNK inhibitors were also effective at blocking the synergistic effect seen in adhesion/migration when sCD40L was added in the presence of a second inflammatory factor, TNF $\alpha$, or a chemoattractant, CCL2/MCP-1.

To ensure that the effects by JNK inhibitors seen in the functional assays are due to JNK inhibition and not that of broad inhibition on other kinases (like ERK); lysates from cells treated with sCD40L or in combination with JNK inhibitor were evaluated. The blots in Figure $5 G$ show the nuclear accumulation of phosphorylated c-jun in the CD40L treated along with its significant reduction in cells that were coincubated with CD40L and JNK inhibitor. In contrast, ERK activation by CD40L was unaffected by the presence of JNK inhibitors (Fig. $5 H$ ). Therefore, adhesion and transendothelial migration stimulated by CD40/ CD40L are mediated by JNK and not by other kinases (like ERK).

\section{Discussion}

CD40/CD40L interactions in endothelial cells have been implicated in several pathologic conditions including atherosclerosis, allograft rejection, Alzheimer's disease (AD), and chronic inflammation (for review, see Town et al., 2001; Phipps, 2008). Using human brain tissues affected by HIVE, we found that prominent upregulation of CD40 in brain endothelium. CD40 expression levels paralleled the severity of HIVE, expression of adhesion molecules, and immune cell infiltration into the neuropile. Since CD40L levels are increased in the blood of HIV-1-infected patients, we investigated whether CD40-CD40L interactions at the $\mathrm{BBB}$ promoted neuroinflammation. Exposure of BMVECs to shown).
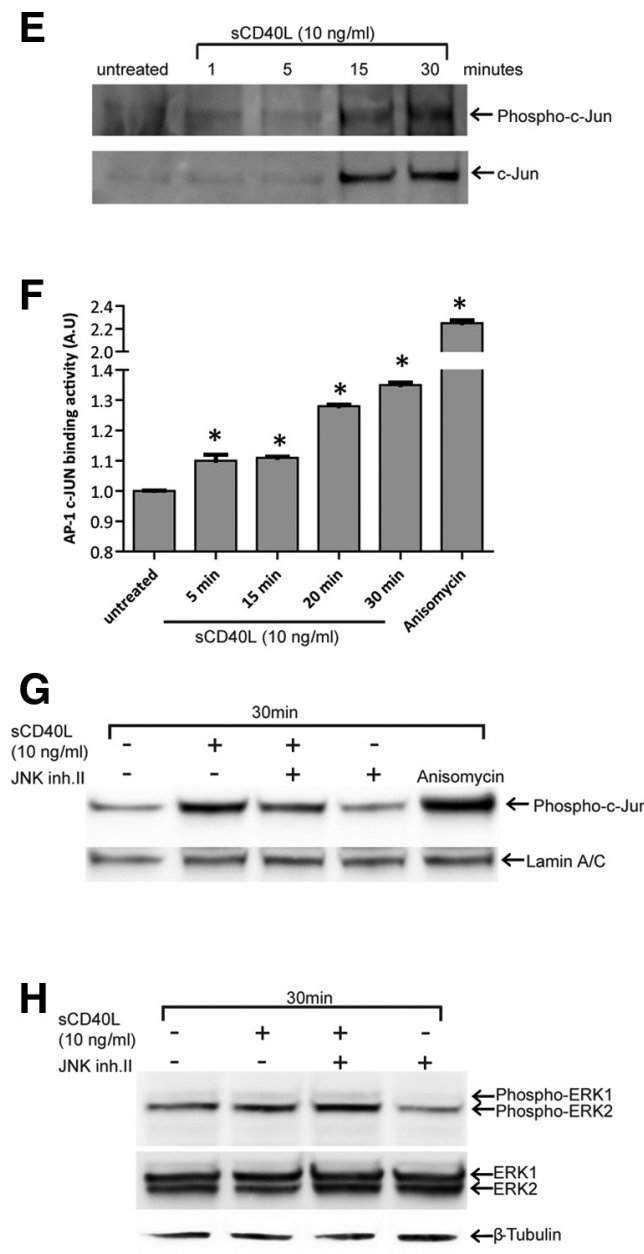

Figure 5. Activation of CD40 in BMVECs leads to ERK1/2 and JNK-1 activation but not p38 MAPK activation. Western blots are hown for the phosphorylated/activated status of ERK1/2, JNK1 and p38 MAPK after CD40 activation. $\boldsymbol{A}$, Western blots for MLK3, 15 , and 30 min, lysed, and Western blots performed. $B$, Phosphorylation of JNK1 (thr183/tyr185) is shown along with densitometry values calculated from the ratio of phospho JNK1/total JNK; the values are expressed as a fold change relative to untreated control. tyr182) is shown. Corresponding blots for total ERK1/2, JNK1, and p38 MAPK protein are shown below the blots probed with the phospho-specific antibody. $\beta$-tubulin was used as the loading control $(\boldsymbol{A}-\boldsymbol{D})$. $\boldsymbol{E}$, Activation of c-JUN was determined by assessing was determined using an ELISA-based transactivation assay. Nuclear extracts from sCD40L-treated BMVECs were prepared for the (I) In contrast to c-JUN, JNK inhibitor II (2 $\mu$ m; SP600125) does not block the activation of ERK after CD40L activation (cytosolic fraction

sCD40L led to a fourfold increase in monocyte adhesion to BMVEC monolayers and paralleled the upregulation of adhesion molecules. Using BBB models, we demonstrated that sCD40L pretreatment of BMVECs produced a fourfold increase in monocyte migration across endothelial monolayers in response to a relevant chemoattractant, CCL2/MCP-1. Next, we defined sCD40L/CD40 signaling in BMVECs, demonstrating fast activation of ERK1/2 and JNK1 in response to CD40L. Interestingly, only inhibition of JNK1 reversed the induction of ICAM-1 and VCAM-1. Activation of the JNK1 pathway by sCD40L led to an increase in phosphorylation, nuclear translocation, and DNA-binding activity of the transcription factor c-Jun. Suppression of JNK1 prevented the enhanced monocyte adhesion to and transendothelial migration across 
A
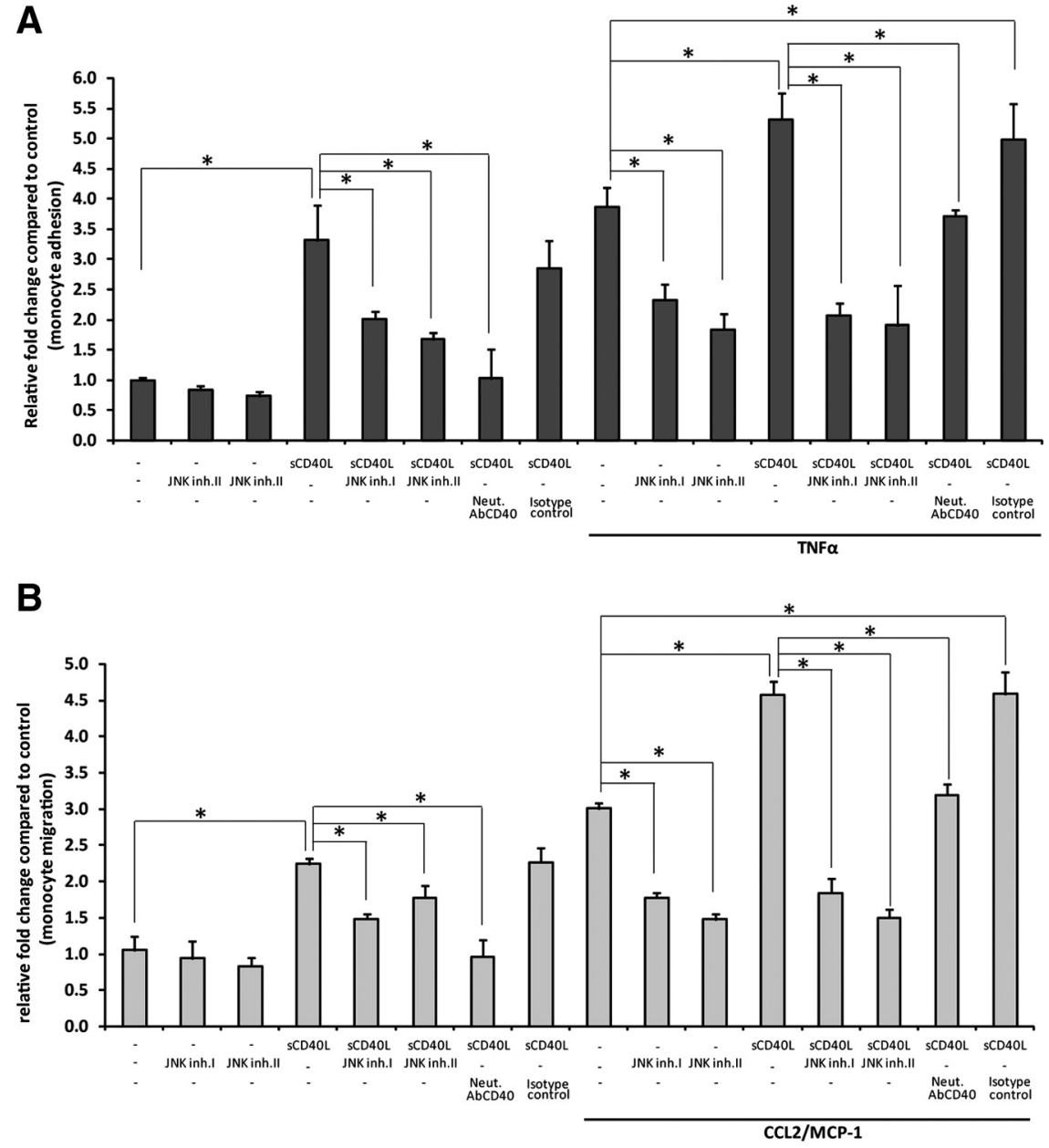

Figure 6. Inhibition of JNK in BMVECs attenuates CD40-mediated monocyte migration. The effect on adhesion and transendothelial migration of monocytes was evaluated in BMVECs exposed to JNK inhibitors coincubated with SCD40L (100 ng/ml). $\boldsymbol{A}$, Adhesion assays of untreated, SCD40L-treated, and TNF $\alpha$-treated endothelial cells exposed to JNK1 inhibitor, JNK binding domain peptide $(10 \mu \mathrm{M})$, and pharmacological JNK1 inhibitor SP600125 $(2 \mu \mathrm{m})$ for $24 \mathrm{~h}$. Before assay, all treatments were removed and calcein-AM-labeled monocytes were added to the BMVECs and allowed to adhere for 15 min, unattached cells were rinsed, and the fluorescence was measured. The data are represented as mean \pm SEM fold difference, which is the adhesion value from treated BMVECs divided by the basal adhesion value from untreated cells. $\boldsymbol{B}$, Transendothelial migration of monocytes was performed across sCD40L-stimulated BMVEC monolayers in the presence of JNK inhibitors. All treatments (as above; except no TNF $\alpha$ ) were removed before monocyte introduction, and, where indicated, chemotaxis was performed toward CCL2/MCP-1 (50 ng/ml). The data are represented as the fold difference (mean \pm SEM) of migration, which is the value from the migration of treated cells divided by the basal migration of untreated cells without chemoattractant. All data collected were from at least three independent experiments performed in triplicate; ${ }^{*} p<0.01$, stastical significance.

BMVEC monolayers exposed to sCD40L. Together, upregulation of CD40 in HIVE brain tissue, and increased monocyte adhesion and transmigration across BMVECs exposed to CD40L, accompanied by an increase in adhesion molecules, point to an important role for the CD40/CD40L dyad in BBB disruption during neuroinflammation.

CD40 belongs to the TNF receptor family and is expressed in immune cells (Chen et al., 2006). CD40 is also detected in nonimmune cells like those comprising the vascular wall, in particular, in endothelial cells (Urbich and Dimmeler, 2004). Activation of CD40 results from engagement to its natural ligand CD40L. sCD40L has similar induction characteristics to the transmembranous form. Triggering of CD40-CD40L interaction initiates multiple signaling cascades that lead to the release of key proinflammatory mediators including interleukin-1 (IL-1), IL-6, IL-8, IL-10, TNF $\alpha$, macrophage inflammatory protein-1 $\alpha$, and CCL2/
MCP-1. Costimulatory molecules (including its own receptor CD40) and adhesion molecules (ICAM-1, VCAM-1, E-selectin) are induced by the CD40/CD40L dyad (Elgueta et al., 2009). In terms of the endothelium, activation of CD40 is a critical component of inflammatory response and a strong contributor to chronic inflammation in cardiovascular disease (Hassan et al., 2009).

In the CNS, a number of studies focusing on neurons and glial cells point to the importance of CD40 in the pathobiology of chronic neuroinflammation (Tan et al., 1999a; Town et al., 2001; Calingasan, 2002). For example, in studies related to $\mathrm{AD}$, exposure of $\beta$-amyloid $(\mathrm{A} \beta)$ peptides to cultured microglia induces the expression of CD40, which is further elevated with the coaddition of interferon- $\gamma$ (Tan et al., 1999b). More importantly, the upregulation of microglial CD40 by $\mathrm{A} \beta_{1-42}$, and in combination with soluble CD40L, results in significant neuronal loss (Tan et al., 1999b). In vivo studies have also shown that the $\beta$-amyloid plaque burden and microgliosis are markedly reduced in TgAPP $_{\text {sw }}$ (AD mouse model) mice crossed with CD40L knock-out mice (Tan et al., 2002b). Therefore, interruption of the CD40/CD40L dyad directly attenuates the neuroinflammation associated with the pathology of $\mathrm{AD}$ (for comprehensive review, see Tan et al., 2002a).

Thus far, the inflammatory contribution of CD40/CD40L in the brain has centered primarily on neurons, astrocytes and microglial cells, while the effects of CD40 on brain endothelial cells remain largely unexplored. The involvement of CD40 in the brain vasculature is underscored in a study by Togo et al. (2000) where strong CD40-positive immunolabeling of cerebral vessels is observed in postmortem tissue from $\mathrm{AD}$ cases and other neurological diseases. The studies reported here provide the first evidence of CD40 upregulation in the brain vasculature in HIVE neuroinflammation.

During HIVE, viral infection of blood-borne or resident CNS macrophages induces reactive astrocytosis, microglial nodules, $\mathrm{BBB}$ dysfunction, and infiltration of monocytes into the perivascular spaces (Boissé et al., 2008). Chronic inflammation in HIVE causes disruption in neuronal networks leading to cognitive deficits (Kaul et al., 2001). The findings presented here demonstrate the abundant upregulation of CD40 in the vasculature of brain tissues affected by HIVE. CD40 levels detected on brain endothelium parallel overexpression of VCAM-1 and ICAM-1 (Persidsky et al., 1997). Our findings complement early studies where a marked increase of CD40 was found in activated microglia in HIVE brain (D'Aversa et al., 2005). It is possible that shed or secreted sCD40L cells by HIV-1-infected cells in the brain exacerbates and perpetuates inflammatory responses by acting on and upregulating CD40 in the 
brain endothelium. Cognitive impairment is clearly associated with BBB impairment (Avison et al., 2004a) and increased levels of CD40L in CSF and serum (Sui et al., 2007).

Activation of the endothelium is a central component of immune-mediated inflammatory diseases of the CNS. In the case of HIVE and multiple sclerosis, immune access to the CNS is a required step in the induction of chronic neuroinflammation (Minagar et al., 2002; Trebst et al., 2003). To evaluate whether CD40L activates brain endothelial cells to allow for increased monocyte-endothelial cell interaction, we performed adhesion assays using primary human BMVECs. We showed that CD40L greatly increased adhesion of monocytes to endothelial cells. Similarly, transendothelial migration was also enhanced in a dose-dependent manner with CD40L. In the presence of a secondary inflammatory mediator such as TNF $\alpha$ or in CCL2/MCP1-driven chemotaxis, sCD40L produces synergistic effects leading to greater adhesion and transendothelial migration. Higher adhesion of resting and activated T-cells to primary BMVECs exposed to sCD40L alone or in combination with TNF $\alpha$ has been shown previously (Omari and Dorovini-Zis, 2003). In addition to increases in cytokine production, activation of the CD40/CD40L promoted expression of adhesion molecules ICAM-1 and VCAM-1 (Elgueta et al., 2009). Our analysis of ICAM- 1 and VCAM-1 indicates SCD40L dose-dependent induction of both adhesion molecules. These results differ from an early report using BMVECs that showed a marginal increase in VCAM-1 after CD40 activation with anti-CD40 antibodies and a high VCAM-1 expression after BMVECs had been exposed to both HIV-1 and CD40 activation (Moses et al., 1997). Perhaps the manner in which CD40 was activated may account for some of the differences since our studies used the CD40L to activate the receptor.

Intracellular signaling events triggered by the CD40/CD40L system have been characterized in immune cells (Elgueta et al., 2009). In the brain, however, the focus on the CD40 pathway activation has centered on microglia, with little known about CD40 signaling in the brain endothelium (Chen et al., 2006). We explored the pathways that are activated by CD40/CD40L and the potential role in neuroinflammation via enhanced expression of ICAM-1 and VCAM-1. Although CD40 lacks intrinsic enzymatic activity, its trimerization with CD40L promotes interaction mainly with the TNF receptor-associated factors (TRAFs). Directly and via the TRAFs, CD40 initiates multiple and diverse signaling cascades involved in inflammation including: JAK/ STAT, IKK/NF $\kappa$ B, p38 MAPK, ERK1/2, and JNK1/AP1 (Elgueta et al., 2009). In the current report, we have systematically inhibited the known pathways that participate in CD40-mediated inflammatory response in BMVECs activated by $\mathrm{sCD} 40 \mathrm{~L}$ and detected a nearly complete inhibition of the two adhesion molecules with JNK-1 inhibitors.

Analysis of phosphorylation status showed that not only JNK1 but also ERK1/2 was rapidly activated by SCD40L. Interestingly, the p38 MAPK appeared active in the BMVECs under resting conditions; however, it was not further activated/phosphorylated by sCD40L. This observation contrasts to a previous study implicating that p38 MAPK activation was involved in cytokine production after CD40 stimulation (Mathur et al., 2004). Our data are different from results obtained using coronary endothelial cells where CD40L increased phosphorylation of MAPK p38 and ERK1/2 supporting important tissue differences between brain and endothelial cells from other tissues (Chen et al., 2008). Since ERK1/2 inhibition did not prevent adhesion molecule upregulation by CD40, we investigated JNK1 activation of its downstream effectors. JNK1 contributes to the inflammatory response via AP-1 transcription factors. Our analysis demonstrates that the AP1 transcription factor c-JUN had increased phosphorylation, nuclear translocation, and DNA-binding activity after CD40 activation. Using human umbilical vein endothelial cells, Xia et al. (2009) reported that the sCD40L-induced shedding of soluble ICAM-1 and VCAM-1 was a JNK-1- and p38 MAPK-mediated phenomenon. Our data also suggest that signal integration from CD40 in the BMVECs may occur via MLK3. Thus, sCD40L engagement of CD40 generates signaling that activates MLK3 $\rightarrow$ JNK1 $\rightarrow$ c-JUN, leading to the induction of ICAM-1 and VCAM-1 in the BMVECs. If JNK1 inhibition blocks adhesion molecule expression by sCD40L, then monocyte adhesion and transendothelial migration would also be affected. The results presented here demonstrate that inhibition of JNK drastically reduces monocyte adhesion to and migration of monocytes across CD40-activated brain endothelial cells. Overall, our findings support the key concept that sCD40L is an important regulator of brain endothelial activation that could potentiate the progression of HIV-1-driven neuroinflammation and HAND. Uncovering the signaling mechanism has significant implications beyond HIV-1 CNS infection, given the observed upregulation of CD40L in Alzheimer's disease, multiple sclerosis, stroke, and numerous inflammatory conditions outside of the brain (Ishikawa et al., 2005; Desideri et al., 2008; Elgueta et al., 2009; Rezai-Zadeh et al., 2009).

The BBB is responsible for maintaining the delicate neuronal environment optimal for synaptic communication. Therefore, it may also be important to understand whether sCD40L breaches barrier function by effects on the tight junction complexes. Supporting this idea is the ability of SCD40L to decrease transendothelial electrical resistance, a measure of barrier "tightness" (unpublished results). Thus, in conjunction with its proinflammatory inducing ability, CD40 may also acts as a BBB modulator.

\section{References}

Avison MJ, Nath A, Greene-Avison R, Schmitt FA, Greenberg RN, Berger JR (2004a) Neuroimaging correlates of HIV-associated BBB compromise. J Neuroimmunol 157:140-146.

Avison MJ, Nath A, Greene-Avison R, Schmitt FA, Bales RA, Ethisham A, Greenberg RN, Berger JR (2004b) Inflammatory changes and breakdown of microvascular integrity in early human immunodeficiency virus dementia. J Neurovirol 10:223-232.

Boissé L, Gill MJ, Power C (2008) HIV infection of the central nervous system: clinical features and neuropathogenesis. Neurol Clin 26:799$819, \mathrm{x}$.

Borda JT, Alvarez X, Mohan M, Hasegawa A, Bernardino A, Jean S, Aye P, Lackner AA (2008) CD163, a marker of perivascular macrophages, is up-regulated by microglia in simian immunodeficiency virus encephalitis after haptoglobin-hemoglobin complex stimulation and is suggestive of breakdown of the blood-brain barrier. Am J Pathol 172:725-737.

Calingasan NY, Erdely HA, Altar CA (2002) Identification of CD40 ligand in Alzheimer's disease and in animal models of Alzheimer's disease and brain injury. Neurobiol Aging 23:31-39.

Chai H, Yan S, Wang H, Zhang R, Lin PH, Yao Q, Chen C (2006) CD40 ligand increases expression of its receptor CD40 in human coronary artery endothelial cells. Surgery 140:236-242.

Chen C, Chai H, Wang X, Jiang J, Jamaluddin MS, Liao D, Zhang Y, Wang H, Bharadwaj U, Zhang S, Li M, Lin P, Yao Q (2008) Soluble CD40 ligand induces endothelial dysfunction in human and porcine coronary artery endothelial cells. Blood 112:3205-3216.

Chen K, Huang J, Gong W, Zhang L, Yu P, Wang JM (2006) CD40/CD40L dyad in the inflammatory and immune responses in the central nervous system. Cell Mol Immunol 3:163-169.

D’Aversa TG, Weidenheim KM, Berman JW (2002) CD40-CD40L interactions induce chemokine expression by human microglia: implications for 
human immunodeficiency virus encephalitis and multiple sclerosis. Am J Pathol 160:559-567.

D’Aversa TG, Eugenin EA, Berman JW (2005) NeuroAIDS: contributions of the human immunodeficiency virus-1 proteins Tat and gp120 as well as CD40 to microglial activation. J Neurosci Res 81:436-446.

Desideri G, Cipollone F, Necozione S, Marini C, Lechiara MC, Taglieri G, Zuliani G, Fellin R, Mezzetti A, di Orio F, Ferri C (2008) Enhanced soluble CD40 ligand and Alzheimer's disease: evidence of a possible pathogenetic role. Neurobiol Aging 29:348-356.

Devaraj S, Glaser N, Griffen S, Wang-Polagruto J, Miguelino E, Jialal I (2006) Increased monocytic activity and biomarkers of inflammation in patients with type 1 diabetes. Diabetes 55:774-779.

Du Y, Böck BC, Schachter KA, Chao M, Gallo KA (2005) Cdc42 induces activation loop phosphorylation and membrane targeting of mixed lineage kinase 3. J Biol Chem 280:42984-42993.

Eilers M, Roy U, Mondal D (2008) MRP (ABCC) transporters-mediated efflux of anti-HIV drugs, saquinavir and zidovudine, from human endothelial cells. Exp Biol Med (Maywood) 233:1149-1160.

Elgueta R, Benson MJ, de Vries VC, Wasiuk A, Guo Y, Noelle RJ (2009) Molecular mechanism and function of CD40/CD40L engagement in the immune system. Immunol Rev 229:152-172.

Eugenin EA, Gamss R, Buckner C, Buono D, Klein RS, Schoenbaum EE, Calderon TM, Berman JW (2006) Shedding of PECAM-1 during HIV infection: a potential role for soluble PECAM-1 in the pathogenesis of NeuroAIDS. J Leukoc Biol 79:444-452.

Hassan GS, Merhi Y, Mourad WM (2009) CD154 and its receptors in inflammatory vascular pathologies. Trends Immunol 30:165-172.

Heeschen C, Dimmeler S, Hamm CW, van den Brand MJ, Boersma E, Zeiher AM, Simoons ML (2003) Soluble CD40 ligand in acute coronary syndromes. N Engl J Med 348:1104-1111.

Ishikawa M, Vowinkel T, Stokes KY, Arumugam TV, Yilmaz G, Nanda A, Granger DN (2005) CD40/CD40 ligand signaling in mouse cerebral microvasculature after focal ischemia/reperfusion. Circulation 111:1690-1696.

Kaul M, Garden GA, Lipton SA (2001) Pathways to neuronal injury and apoptosis in HIV-1-associated dementia. Nature 410:988-994.

Kehry MR, Castle BE (1994) Regulation of CD40 ligand expression and use of recombinant CD40 ligand for studying B cell growth and differentiation. Semin Immunol 6:287-294.

Kim WK, Alvarez X, Fisher J, Bronfin B, Westmoreland S, McLaurin J, Williams K (2006) CD163 identifies perivascular macrophages in nor$\mathrm{mal}$ and viral encephalitic brains and potential precursors to perivascular macrophages in blood. Am J Pathol 168:822-834.

Klein B, Tarte K, Jourdan M, Mathouk K, Moreaux J, Jourdan E, Legouffe E, De Vos J, Rossi JF (2003) Survival and proliferation factors of normal and malignant plasma cells. Int J Hematol 78:106-113.

Li H, Nord EP (2009) IL-8 amplifies CD40/CD154-mediated ICAM-1 production via the CXCR-1 receptor and p38-MAPK pathway in human renal proximal tubule cells. Am J Physiol Renal Physiol 296:F438-445.

Li N (2008) Platelet-lymphocyte cross-talk. J Leukoc Biol 83:1069-1078.

Mancino A, Schioppa T, Larghi P, Pasqualini F, Nebuloni M, Chen IH, Sozzani S, Austyn JM, Mantovani A, Sica A (2008) Divergent effects of hypoxia on dendritic cell functions. Blood 112:3723-3734.

Mathur RK, Awasthi A, Wadhone P, Ramanamurthy B, Saha B (2004) Reciprocal CD40 signals through p38MAPK and ERK-1/2 induce counteracting immune responses. Nat Med 10:540-544.

Minagar A, Shapshak P, Fujimura R, Ownby R, Heyes M, Eisdorfer C (2002) The role of macrophage/microglia and astrocytes in the pathogenesis of three neurologic disorders: HIV-associated dementia, Alzheimer disease, and multiple sclerosis. J Neurol Sci 202:13-23.

Minagar A, Commins D, Alexander JS, Hoque R, Chiappelli F, Singer EJ, Nikbin B, Shapshak P (2008) NeuroAIDS: characteristics and diagnosis of the neurological complications of AIDS. Mol Diagn Ther 12:25-43.

Mondal D, Pradhan L, Ali M, Agrawal KC (2004) HAART drugs induce oxidative stress in human endothelial cells and increase endothelial recruitment of mononuclear cells: exacerbation by inflammatory cytokines and amelioration by antioxidants. Cardiovasc Toxicol 4:287-302.

Moses AV, Williams SE, Strussenberg JG, Heneveld ML, Ruhl RA, Bakke AC, Bagby GC, Nelson JA (1997) HIV-1 induction of CD40 on endothelial cells promotes the outgrowth of AIDS-associated B-cell lymphomas. Nat Med 3:1242-1249.

Omari KM, Dorovini-Zis K (2003) CD40 expressed by human brain endo- thelial cells regulates $\mathrm{CD} 4+\mathrm{T}$ cell adhesion to endothelium. J Neuroimmunol 134:166-178.

Persidsky Y, Stins M, Way D, Witte MH, Weinand M, Kim KS, Bock P, Gendelman HE, Fiala M (1997) A model for monocyte migration through the blood-brain barrier during HIV-1 encephalitis. J Immunol 158:3499-3510.

Persidsky Y, Ghorpade A, Rasmussen J, Limoges J, Liu XJ, Stins M, Fiala M, Way D, Kim KS, Witte MH, Weinand M, Carhart L, Gendelman HE (1999) Microglial and astrocyte chemokines regulate monocyte migration through the blood-brain barrier in human immunodeficiency virus-1 encephalitis. Am J Pathol 155:1599-1611.

Persidsky Y, Ramirez SH, Haorah J, Kanmogne GD (2006a) Blood-brain barrier: structural components and function under physiologic and pathologic conditions. J Neuroimmune Pharmacol 1:223-236.

Persidsky Y, Heilman D, Haorah J, Zelivyanskaya M, Persidsky R, Weber GA, Shimokawa H, Kaibuchi K, Ikezu T (2006b) Rho-mediated regulation of tight junctions during monocyte migration across the blood-brain barrier in HIV-1 encephalitis (HIVE). Blood 107:4770-4780.

Phipps RP (2008) CD40: lord of the endothelial cell. Blood 112:3531-3532. Piguet PF, Kan CD, Vesin C, Rochat A, Donati Y, Barazzone C (2001) Role of CD40-CVD40L in mouse severe malaria. Am J Pathol 159:733-742.

Pluvinet R, Olivar R, Krupinski J, Herrero-Fresneda I, Luque A, Torras J, Cruzado JM, Grinyó JM, Sumoy L, Aran JM (2008) CD40: an upstream master switch for endothelial cell activation uncovered by RNAi-coupled transcriptional profiling. Blood 112:3624-3637.

Ramirez SH, Heilman D, Morsey B, Potula R, Haorah J, Persidsky Y (2008) Activation of peroxisome proliferator-activated receptor gamma (PPARgamma) suppresses Rho GTPases in human brain microvascular endothelial cells and inhibits adhesion and transendothelial migration of HIV-1 infected monocytes. J Immunol 180:1854-1865.

Ramirez SH, Potula R, Fan S, Eidem T, Papugani A, Reichenbach N, Dykstra H, Weksler BB, Romero IA, Couraud PO, Persidsky Y (2009) Methamphetamine disrupts blood-brain barrier function by induction of oxidative stress in brain endothelial cells. J Cereb Blood Flow Metab 29:1933-1945

Ray DM, Akbiyik F, Bernstein SH, Phipps RP (2005) CD40 engagement prevents peroxisome proliferator-activated receptor gamma agonistinduced apoptosis of B lymphocytes and B lymphoma cells by an NFkappaB-dependent mechanism. J Immunol 174:4060-4069.

Rezai-Zadeh K, Gate D, Town T (2009) CNS infiltration of peripheral immune cells: D-Day for neurodegenerative disease? J Neuroimmune Pharmacol 4:462-475.

Rizvi M, Pathak D, Freedman JE, Chakrabarti S (2008) CD40-CD40 ligand interactions in oxidative stress, inflammation and vascular disease. Trends Mol Med 14:530-538.

Ryan EP, Pollock SJ, Murant TI, Bernstein SH, Felgar RE, Phipps RP (2005) Activated human B lymphocytes express cyclooxygenase-2 and cyclooxygenase inhibitors attenuate antibody production. J Immunol 174:2619-2626.

Schwabe RF, Schnabl B, Kweon YO, Brenner DA (2001) CD40 activates NF-kappa B and c-Jun N-terminal kinase and enhances chemokine secretion on activated human hepatic stellate cells. J Immunol 166:6812-6819.

Sharief MK, Ciardi M, Thompson EJ, Sorice F, Rossi F, Vullo V, Cirelli A (1992) Tumour necrosis factor-alpha mediates blood-brain barrier damage in HIV-1 infection of the central nervous system. Mediators Inflamm 1:191-196.

Sipsas NV, Sfikakis PP, Kontos A, Kordossis T (2002) Levels of soluble CD40 ligand (CD154) in serum are increased in human immunodeficiency virus type 1 -infected patients and correlate with CD4(+) T-cell counts. Clin Diagn Lab Immunol 9:558-561.

Sitati E, McCandless EE, Klein RS, Diamond MS (2007) CD40-CD40 ligand interactions promote trafficking of CD8 + T cells into the brain and protection against West Nile virus encephalitis. J Virol 81:9801-9811.

Sui Z, Sniderhan LF, Schifitto G, Phipps RP, Gelbard HA, Dewhurst S, Maggirwar SB (2007) Functional synergy between CD40 ligand and HIV-1 Tat contributes to inflammation: implications in HIV type 1 dementia. J Immunol 178:3226-3236.

Tan J, Town T, Paris D, Placzek A, Parker T, Crawford F, Yu H, Humphrey J, Mullan M (1999a) Activation of microglial cells by the CD40 pathway: relevance to multiple sclerosis. J Neuroimmunol 97:77-85.

Tan J, Town T, Paris D, Mori T, Suo Z, Crawford F, Mattson MP, Flavell RA, 
Mullan M (1999b) Microglial activation resulting from CD40-CD40L interaction after beta-amyloid stimulation. Science 286:2352-2355.

Tan J, Town T, Mullan M (2002a) CD40-CD40L interaction in Alzheimer's disease. Curr Opin Pharmacol 2:445-451.

Tan J, Town T, Crawford F, Mori T, DelleDonne A, Crescentini R, Obregon D, Flavell RA, Mullan MJ (2002b) Role of CD40 ligand in amyloidosis in transgenic Alzheimer's mice. Nat Neurosci 5:1288-1293.

Togo T, Akiyama H, Kondo H, Ikeda K, Kato M, Iseki E, Kosaka K (2000) Expression of CD40 in the brain of Alzheimer's disease and other neurological diseases. Brain Res 885:117-121.

Town T, Tan J, Mullan M (2001) CD40 signaling and Alzheimer's disease pathogenesis. Neurochem Int 39:371-380.

Town T, Laouar Y, Pittenger C, Mori T, Szekely CA, Tan J, Duman RS, Flavell RA (2008) Blocking TGF-beta-Smad2/3 innate immune signaling mitigates Alzheimer-like pathology. Nat Med 14:681-687.

Trebst C, Staugaitis SM, Tucky B, Wei T, Suzuki K, Aldape KD, Pardo CA, Troncoso J, Lassmann H, Ransohoff RM (2003) Chemokine receptors on infiltrating leucocytes in inflammatory pathologies of the central nervous system (CNS). Neuropathol Appl Neurobiol 29:584-595.

Tsakiris DA, Tschöpl M, Wolf F, Labs KH, Jäger KA, Marbet GA (2000) Platelets and cytokines in concert with endothelial activation in patients with peripheral arterial occlusive disease. Blood Coagul Fibrinolysis 11:165-173.

Urbich C, Dimmeler S (2004) CD40 and vascular inflammation. Can J Cardiol 20:681-683.

Xia M, Ling W, Zhu H, Ma J, Wang Q, Hou M, Tang Z, Guo H, Liu C, Ye Q (2009) Anthocyanin attenuates CD40-mediated endothelial cell activation and apoptosis by inhibiting CD40-induced MAPK activation. Atherosclerosis 202:41-47.

Yu Q, Kovacs C, Yue FY, Ostrowski MA (2004) The role of the p38 mitogenactivated protein kinase, extracellular signal-regulated kinase, and phosphoinositide-3-OH kinase signal transduction pathways in CD40 ligand-induced dendritic cell activation and expansion of virus-specific CD8 + T cell memory responses. J Immunol 172:6047-6056. 